\title{
A hierarchy of SSB protomers in replication protein $\mathbf{A}$
}

\author{
Doranelly Philipova, Janet R. Mullen, Hina S. Maniar, Jian Lu, Chunyan Gu, and Steven J. Brill ${ }^{1}$ \\ Department of Molecular Biology and Biochemistry, Center for Advanced Biotechnology and Medicine, Rutgers University, \\ Piscataway, New Jersey 08855 USA
}

Replication Protein A (RPA) is a heterotrimeric single-stranded DNA-binding protein (SSB) found in all eukaryotic cells. RPA is known to be required for many of the same reactions catalyzed by the homotetrameric SSB of bacteria, but its origin, subunit functions, and mechanism of binding remain a mystery. Here we show that the three subunits of yeast RPA contain a total of four domains with weak sequence similarity to the Escherichia coli SSB protomer. We refer to these four regions as potential ssDNA-binding domains (SBDs). The p69 subunit, which is known to bind ssDNA on its own, contains two SBDs that together confer stable binding to ssDNA. The p36 and p13 subunits each contain a single SBD that does not bind stably, but corresponds to the minimal region required for viability in yeast. Photocross-linking of recombinant protein to ssDNA indicates that an SBD consists of $\sim 120$ amino acids with two centrally located aromatic residues. Mutation of these aromatic residues inactivates ssDNA binding and is a lethal event in three of the four domains. Finally, we present evidence that the p36 subunit binds ssDNA, as part of the RPA complex, in a salt-dependent reaction similar to the wrapping of ssDNA about $E$. coli SSB. The results are consistent with the notion that RPA arose by duplication of an ancestral SSB gene and that tetrameric ssDNA-binding domains and higher order binding are essential features of cellular SSBs.

[Key Words: SSB; DNA Replication; replication protein A; yeast]

Received May 7, 1996; revised version accepted July 24, 1996.

As participants in most aspects of DNA metabolism, single-stranded DNA-binding proteins (SSBs) play a crucial role in the control of genetic information. The two cellular SSBs, Escherichia coli SSB (Ecssb) and replication protein A (RPA), bear little structural or amino acid sequence similarity but carry out many of the same essential functions in DNA replication, repair, and recombination. Because many eukaryotic DNA replication proteins show sequence similarity to their homologs in $E$. coli (O'Donnell et al. 1993), an analysis of RPA should begin with a focus on the critical features of Ecssb.

Ecssb is composed of four identical $19-\mathrm{kD}$ protomers and displays at least two well-characterized DNA-binding modes (Lohman and Ferrari 1994). Using homopolymer ssDNA and low salt concentration $(<10 \mathrm{~mm} \mathrm{NaCl})$, two protomers bind 35 nucleotides of ssDNA; but at concentrations $\geqslant 0.2 \mathrm{M} \mathrm{NaCl}$, all four protomers bind 65 nucleotides of ssDNA (Lohman and Overman 1985; Lohman and Ferrari 1994). The 65-nucleotide binding mode causes compaction of the ssDNA because of higher order binding or "wrapping" about the tetramer (Chrysogelos and Griffith 1982; Griffith et al. 1984; Bujalowski et al. 1988). When M13 ssDNA is used in place of homopolymer, this larger binding mode is estimated at 91 nucleotides (Rigler and Romano 1995); however, the biological

${ }^{1}$ Corresponding author. roles of the two binding modes are unknown. The residues $\mathrm{W} 40, \mathrm{~W} 54$, and F60 are important for ssDNA binding by Ecssb. The fluorescence of residues W40 and W54 is quenched with binding (Khamis et al. 1987), suggesting that they lie near the ssDNA. W54 and F60 probably contact the ssDNA, because the mutation W54S eliminates the 65-nucleotide binding mode (Carlini et al. 1993. Curth et al. 1993 and F60 can be UV cross-linked to ssDNA (Merrill et al. 1984). Mutation of either W54 or F60 reduces the affinity for ssDNA, presumably by disrupting stacking interactions with the DNA bases $1 \mathrm{Ca}$ sas-Finet et al. 1987; Khamis et al. 1987; Bayer et al. 1989).

Human RPA (HsRPA) is a heterotrimeric complex of $70-, 34-$, and $11-\mathrm{kD}$ subunits that is required for Simian virus 40 (SV40) DNA replication in vitro (Wobbe et al. 1987; Fairman and Stillman 1988; Wold and Kelly 1988). Yeast RPA (ScRPA) was identified as a complex of 69-, 36-, and 13-kD subunits and each subunit is essential for viability (Brill and Stillman 1989, 1991; Heyer et al. 1990). Like Ecssb, RPA is involved in DNA repair (Coverley et al. 1991; Guzder et al. 1995; He et al. 1995) and recombination (Moore et al. 1991; Smith and Rothstein 1995). Although the large subunit has been shown to have ssDNA-binding activity (Wold et al. 1989; Erdile et al. 1991), little is known about the function of the two smaller subunits. Furthermore, at least three different 
binding-site sizes have been reported for RPA. RPA from several species has been shown to interact with $\sim 30 \mathrm{nu}-$ clcotides of ssDNA per trimer (Atrazhev et al. 1992; Kim et al. 1992, 1994; Mitsis et al. 1993). However, glutaraldehyde cross-linking reveals an 8- to 10-nucleotide binding mode for HsRPA (Blackwell and Borowiec 1994), and a binding-site size of 90 nucleotides was originally reported for ScRPA (Alani et al. 1992).

A number of unique roles have been suggested for RPA. For example, it has been proposed to link transcription to DNA replication by interactions with the transcriptional activators VP16, GAL4, and p53 (Dutta ct al. 1993; He et al. 1993; Li and Botchan 1993|. The cellcycle-dependent phosphorylation of p34 suggested a regulatory role for this subunit (Din et al. 1990; Dutta and Stillman 1992; Fotedar and Roberts 1992), and it has been proposed to act as a liccnsing factor in regulating DNA replication (Cardoso et al. 1993). Furthermore, ScRPA has been proposed to regulate transcription as a sequence-specific dsDNA-binding protein in yeast (Luche et al. 1993; Singh and Samson 1995).

To identify the functional domains of RPA, we performed a structure/function analysis of each subunit in yeast. Virtually all of p69 was essential, but large regions of $\mathrm{p} 36$ and $\mathrm{p} 13$ were dispensable for viability. Within the essential regions of the three subunits we identified four domains (SBDs) with weak sequence similaritics to the ssDNA-binding region of the Ecssb protomer. An SBD is a region of $\sim 120$ amino acids containing two centrally located aromatic residues that are important for both ssDNA binding and viability in yeast; therefore, RPA resembles Ecssb in its tetrameric domain structure. Moreover, we present evidence consistent with the idea that ScRPA has multiple ssDNA-binding modes similar to those of Ecssb. Our results explain the discrepancy in RPA binding-sitc sizes and suggest an evolutionary relationship between RPA and Ecssb.

\section{Results}

The minimal essential regions of RPA2 and RPA3 resemble an sSDNA-binding domain

To identify functional domains of the RPA polypeptides in yeast, truncations of each gene were tested for the ability to support growth of a strain lacking the wildtype gene using a "plasmid shuffle" strategy. We constructed yeast strains in which the wild-type copy of RFA1 (encoding RPAl, or the $69-\mathrm{kD}$ subunit), RFA2 (encoding RPA2, or the $36-\mathrm{kD}$ subunit), or RFA3 (encoding $\mathrm{RPA} 3$, or the $13-\mathrm{kD}$ subunit) was deleted and viability was dependent on a plasmid carrying the corresponding wild-type gene on a URA3 vector. Complementation of the null mutation in these yeast strains (SBY102, SBY105, SBY111, respectively) was tested by transforming RFA gene truncations into the appropriate strain on a second vector and determining whether the transformants could survive in the presence of 5-fluoro-orotic acid (FOA), which selects for the loss of the URA3 plasmid (Boeke et al. 1987).
As shown in Figure 1, deletion of 10 amino acids from the amino terminus of the RPA1 protein /construction $1 \mathrm{~N} 10)$ conferred extremely poor growth at both temperatures tested, and deletion of 20 amino acids resulted in loss of viability. No carboxy-terminal residues could be deleted from RPA1 without loss of viability. In contrast, RPA2 could tolerate large truncations from both the amino and carboxyl termini. The largest viable truncations $2 \mathrm{~N} 40$ and $2 \mathrm{C} 100$ were combined to yield the double truncation allele $r f a 2-N 40 / C 100$. This allele, which produces a 133-amino acid protein, conferred viability although it was temperature sensitive (ts) at $37^{\circ} \mathrm{C}$, as was the rfa2-C100 single truncation. RPA3 could also tolerate large amino-terminal truncations, but no carboxyterminal truncations. The largest viable truncation, rfa3-N70, encoding a 52-amino acid protein, was ts for growth at $37^{\circ} \mathrm{C}$.

We searched for amino acid sequence similarity between the minimal essential regions of RPA2 and RPA3, but failed to find any by pairwise comparison. But, when a multiple sequence alignment of the corresponding regions from several species was performed, some residues in RPA2 and RPA3 were found to be similar. Figure 2 shows an amino acid sequence alignment of RPA2 and RPA3 from all published species, along with Ecssb. Shaded horizontally in Figure 2 are the minimal essential residues of RPA2 and RPA3 from yeast. Shaded vertically are the residues corresponding to three aromatic residues that are important for ssDNA binding in Ecssb. By this alignment the entire length of the RPA3 protein falls within the essential region of RPA2, and the region of greatest similarity between the two proteins is found near the essential residues corresponding to W54 and F60 of Ecssb. Although the "W54" and "F60" residues are conserved as aromatic amino acids in all RPA2 and RPA3 proteins, they are spaced 11 residues apart, as opposed to 7 residues in Ecssb. Aromaticity at these positions appears to be critical as judged by Crithidia RPA2. This protcin can probably tolerate a "basic" histidine residuc at this position because of the aromatic nature of the imidazole ring. The proline at the $\mathrm{F} 60$ position of HsRPA4 is an apparent exception to this rule, but RPA4 has not yet been found in a functional RPA complex (Keshav et al. 1995). RPA2, but not RPA3, has conserved the aromatic residue corresponding to W40 in Ecssb, suggesting that this subunit may be more important in ssDNA binding.

The nonessential carboxy-terminal region of RPA2 shows very little similarity to the carboxy-terminal region of Ecssb. The "tail" of Ecssb (residues 116-177) is rich in QPSG residues as are both the amino- and carboxy-terminal nonessential regions of the RPA2 proteins. Interestingly, this tail region of Ecssb has been shown to be dispensable for function in vitro (Williams et al. 1983). Furthermore, the tail is absent in eukaryotic mitochondrial SSBs (mtSSBs), which are known to be related to bacterial SSB (Ghrir et al. 1991; Van Dyck et al. 1992; Tiranti et al. 1993; Thommes et al. 1995). mtSSBs are purificd as homotetrameric complexes of $13-\mathrm{kD}$ subunits with essentially identical properties to Ecssb /Van 
Philipova et al.

\begin{tabular}{|c|c|c|}
\hline $\begin{array}{l}\text { NAME/ } \\
\text { RESIDUES } \\
\text { DELETED } \\
\end{array}$ & $\begin{array}{l}\text { DELETION ANALYSIS } \\
\qquad \mathrm{wt}=621 \text { aa }\end{array}$ & $\frac{\text { VIABILITY }}{30^{\circ} \mathrm{C} 37^{\circ} \mathrm{C}}$ \\
\hline WT & COOH & $+\quad+$ \\
\hline $1 \mathrm{~N} 10$ & & $+1-+1-$ \\
\hline $1 \mathrm{~N} 20$ & 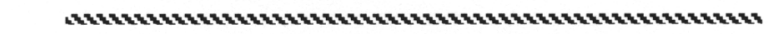 & - \\
\hline $1 \mathrm{~N} 30$ & 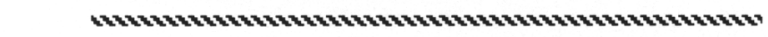 & - \\
\hline $1 \mathrm{~N} 40$ & 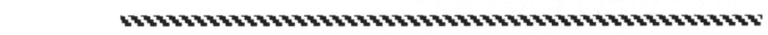 & - \\
\hline $1 \mathrm{C} 10$ & 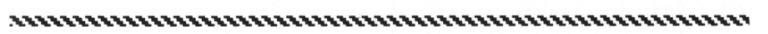 & - \\
\hline $1 \mathrm{C} 20$ & & - \\
\hline $1 \mathrm{C} 30$ & 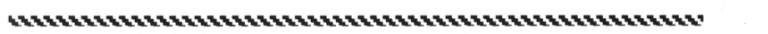 & - \\
\hline
\end{tabular}

\begin{tabular}{|c|c|c|}
\hline $\begin{array}{l}\text { NAME/ } \\
\text { RESIDUES } \\
\text { DELETED }\end{array}$ & $\begin{array}{c}\text { DELETION ANALYSIS } \\
\mathbf{w t}=273 \mathrm{aa}\end{array}$ & VIABILITY \\
\hline WT & BRA2 & $+\quad+$ \\
\hline $2 \mathrm{~N} 10$ & & + \\
\hline $2 \mathrm{~N} 20$ & & + \\
\hline $2 \mathrm{~N} 30$ & & + \\
\hline $2 \mathrm{~N} 40$ & & + \\
\hline $2 \mathrm{~N} 50$ & 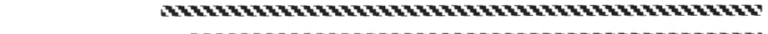 & - \\
\hline $2 \mathrm{~N} 60$ & 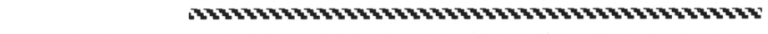 & - \\
\hline 2N70 & 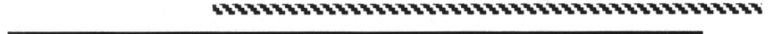 & - \\
\hline $2 \mathrm{C} 20$ & & + \\
\hline $2 \mathrm{C} 40$ & & + \\
\hline $2 \mathrm{C} 60$ & & + \\
\hline $2 \mathrm{C} 80$ & & $+\quad+$ \\
\hline 2C100 & & + \\
\hline $2 \mathrm{C} 110$ & 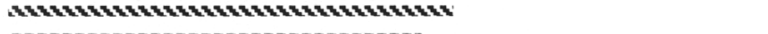 & - \\
\hline $2 \mathrm{C} 120$ & 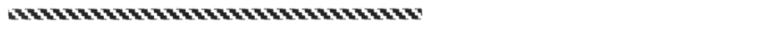 & - \\
\hline $2 \mathrm{~N} 40 / \mathrm{C} 1$ & & + \\
\hline
\end{tabular}

Figure 1. Structure/function analysis of the individual subunits of RPA in yeast. Truncation alleles of the RFA1, RFA2, and RFA3 genes were constructed by PCR in 10-amino acid increments, cloned into a centromeric vector, and introduced into the yeast strains SBY102, SBY105, and SBY111, respectively. Transformants were then streaked onto medium containing FOA and placed at $30^{\circ} \mathrm{C}$ or $37^{\circ} \mathrm{C}$. Filled bars represent polypeptides capable of complementing the null mutation and cross-hatched bars represent polypeptides that fail to complement. The $3 \mathrm{~N} 10$ construction may encode an unstable protein that is unable to complement the null mutation.

\begin{tabular}{|c|c|c|}
\hline $\begin{array}{c}\text { NAME/ } \\
\text { RESIDUES } \\
\text { DELETED }\end{array}$ & $\begin{array}{l}\text { DELETION ANALYSIS } \\
\qquad \mathrm{wt}=\mathbf{1 2 2} \mathrm{aa}\end{array}$ & VIABILITY \\
\hline WT & 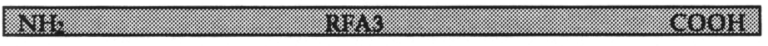 & + \\
\hline $3 N 10$ & & - \\
\hline $3 \mathrm{~N} 20$ & & + \\
\hline $3 \mathrm{~N} 30$ & & + \\
\hline $3 \mathrm{~N} 40$ & & + \\
\hline $3 N 50$ & & + \\
\hline $3 \mathrm{~N} 60$ & & + \\
\hline $3 \mathrm{~N} 70$ & & + \\
\hline $3 \mathrm{~N} 80$ & 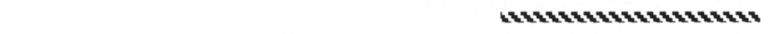 & - \\
\hline $3 \mathrm{C} 10$ & 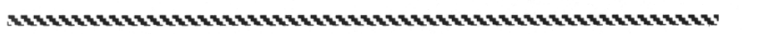 & - \\
\hline $3 \mathrm{C} 20$ & 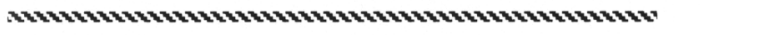 & - \\
\hline $3 \mathrm{C} 30$ & 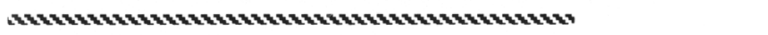 & - \\
\hline $3 C 40$ & 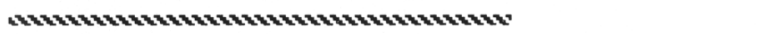 & - \\
\hline $3 \mathrm{C} 50$ & 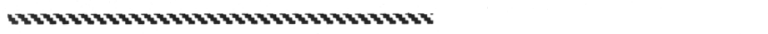 & - \\
\hline
\end{tabular}

Dyck et al. 1992; Curth et al. 1994). In all three cases, only the 120-amino acid region surrounding the invariant aromatic residues corresponding to $\mathrm{W} 54$ and $\mathrm{F} 60$ are essential for SSB activity. We refer to this region in RPA2 and RPA3 as a potential "ssDNA-binding domain" or SBD.

\section{RPA1 contains two additional SBDs}

A multiple-sequence alignment of all known RPAl sequences against the 115-amino acid ssDNA-binding re- gion of Ecssb identified one SBD and visual inspection of RPA1 proteins revealed a second SBD lying in tandem with the first domain. We refer to these amino- and carboxy-terminal SBDs in RPAl as SBD-A and SBD-B, respectively. Figure 3 presents an amino acid sequence alignment of the $\mathrm{A}$ and $\mathrm{B}$ domains versus Ecssb. The greatest degree of similarity between the two domains is found again in the region corresponding to W54 and F60 of Ecssb. But, in constrast to p36 and p13, the residues corresponding to W54 and F60 in RPAl are spaced 8 residues apart. We do note two differences between the A 


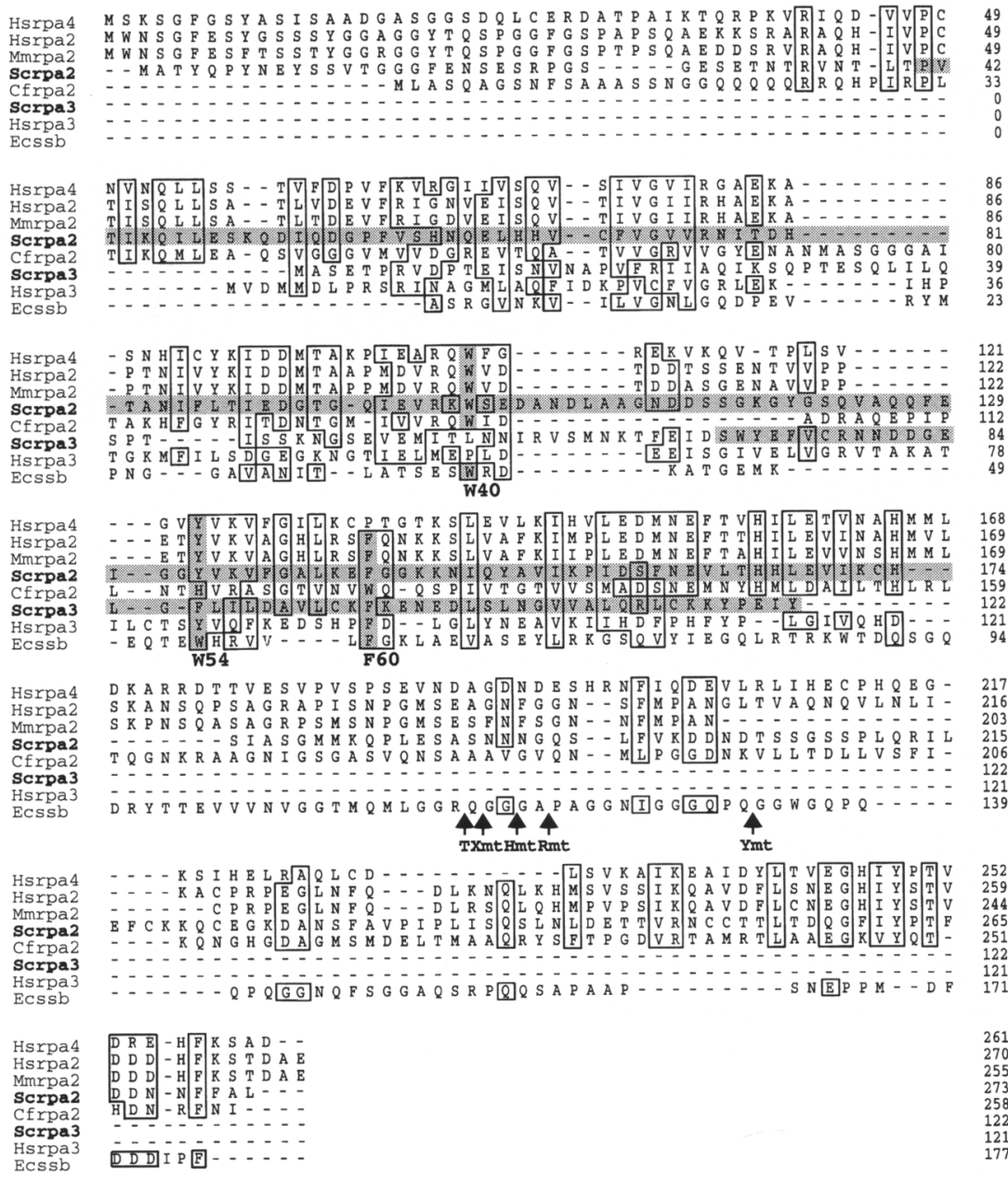

Figure 2. Amino acid sequence comparison of RPA2 and RPA3 homologs. Amino acid sequences were aligned initially using the PILEUP program in the GCG package and then adjusted by eye. Similar residues were boxed with the PRETTYPLOT program using a threshold value of 0.7 and the Blossum 62 similarity matrix. Horizontally shaded sequences are the minimal essential residues of ScRPA2 and ScRPA3 as determined in Fig. 1. Vertically shaded residues correspond to the aromatic residues known to be important for ssDNA binding by E. coli SSB. Arrows represent either the carboxy-terminal end point of E. coli SSB when cleaved by trypsin $(\mathrm{T})$, or the relative position of the end points of $\mathrm{mtSSBs}$ from Xenopus (Xmt), human (Hmt), rat $(\mathrm{Rmt})$, and yeast (Ymt). Sequences were obtained from GenBank. (Hsrpa4) Human RPA4 (U24186); (Hsrpa2) human RPA2 (J05249); (Mmrpa1) mouse RPA2 (D00812); (Scrpa2) yeast RPA2 (X59749); (Cfrpa2) Crithidia RPA2 (Z23164); (Scrpa3) yeast RPA3 (X59750); (Hsrpa3) human RPA3 (L07493), (Ecssb) E. coli SSB (J01704). and $\mathrm{B}$ domains of $\mathrm{RPA} 1$; the $\mathrm{W} 40$ residue is conserved as an aromatic residue only in SBD-A, and SBD-B has three small insertions of 4,6 , and 8 amino acids, relative to the A domain, making it somewhat larger in size.

Random mutagenesis of RFA1 has provided us with evidence of a functional repeating unit in RPA1. Seven- teen groups of charged residues throughout ScRPAl were changed to alanine residues in a failed attempt to generate temperature-sensitive RPA1 mutants. These 17 alleles were then tested for complementation of the hyperrecombinational mutation rfa1-D228Y within SBD-A (shaded in Fig. 3; Smith and Rothstein 1995). Interest-
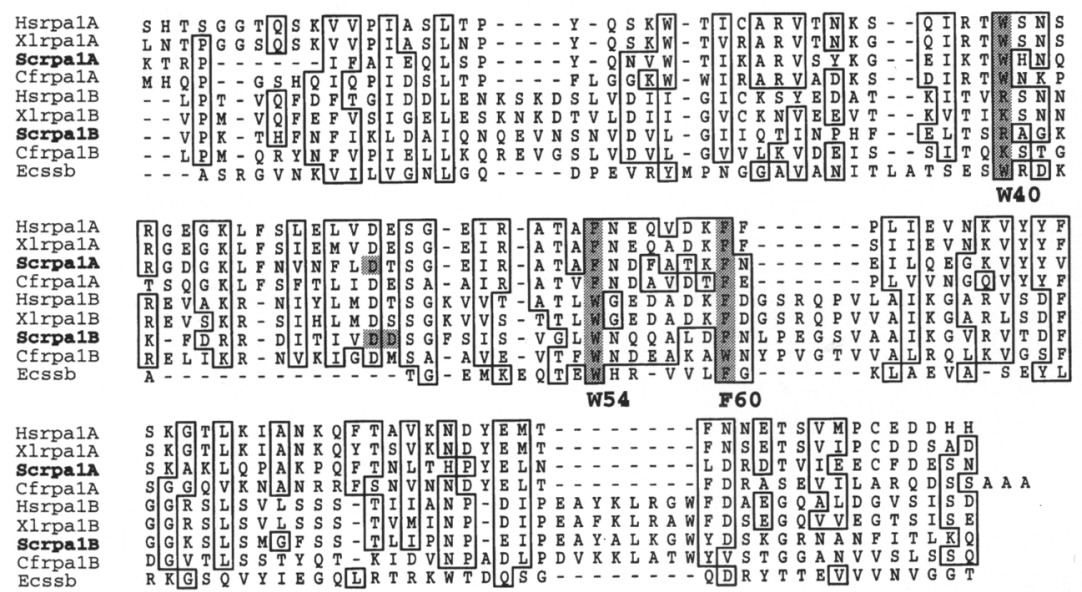

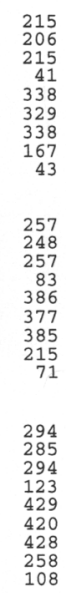

Figure 3. Amino acid sequence comparison of RPA1 domains A and B. Amino acid sequences were aligned as in Fig. 2. Sequences were obtained from GenBank. (HsrpalA) Human RPAl (M63488) residues $174-294, \quad B=$ residues $295-429$; (XlrpalA) Xenopus RPAl (X67240) residues $\quad 165-285, \quad B=$ residues $\quad 285-420$; (ScrpalA) yeast RPA1 (X59748) residues 180-294, B =295-428; CfrpalA, Crithidia $\mathrm{RPAl}$ (Z23163) residues $1-123, \mathrm{~B}=124$ 258; (Ecssb) E. coli SSB (J01704). 
ingly, the double alanine mutation at residues $349 / 350$ within SBD-B (shaded in Fig. 3) was one of only two mutants that failed to complement the rfa1-D228Y allele, which indicates that D349A/D350A must also be a hyper-recombinational allele (J. Smith and R. Rothstein, pers. comm.). Because D228 and D349 occupy identical positions within the proposed repeating unit of RPAl, we conclude that corresponding mutations in either domain A or domain B result in similar phenotypes.

\section{An individual $S B D$ binds $s S D N A$ with low affinity}

To confirm that the SBD-A and SBD-B domains are analogous to the SSB protomer, we expressed recombinant protein and characterized their ssDNA-binding activity in vitro. We were unable to demonstrate stable binding by gel shift analysis with any single SBD alone (data not shown|. But UV cross-linking revealed that a single SBD-A or SBD-B domain could bind a labeled 17-mer oligonucleotide as determined by gel shift analysis (Fig. 4 , lanes $4,9 \mid$. Negative control extracts showed a smear of labeled material that was dependent on UV (lane 2). SBD binding was judged to be weak as it was sensitive to 0.1 $\mathrm{M} \mathrm{NaCl}$, but it was resistant to added double-stranded DNA (dsDNA). Nonspecific ssDNA did compete for binding, which indicates that SBD binding is specific for ssDNA (lanes 7,12), and higher amounts of competitor completely inhibited binding (data not shown). These data are reminiscent of the Ecssb protomer that can bind ssDNA on its own, but with 10-fold lower affinity than the tetramer (Bujalowski and Lohman 1991). We estimated the binding-site size of SBD-A using the gel shift assay and a 64-mer oligonucleotide. Figure 4, lanes 13-18 show that as the concentration of protein extract was increased, multiple bands with lower mobility appeared. At saturation, four SBDs bound the 64-mer oligonucleotide, suggesting a binding-site size of $\sim 16$ nucleotides per SBD. This result is strikingly similar to the known binding-site size for an Ecssb protomer (Lohman and Ferrari 1994).

\section{Domains $A$ and $B$ are partially interchangeable in vivo}

To further define the functional properties of these ssDNA-binding domains, we constructed a plasmid in which the two RPAl SBDs could be mutated and tested for in vivo function. Plasmid pDS1, which contains essentially wild-type RFA1 with unique restriction sites engineered to flank the SBDs, was shown to confer wildtype growth on strain SBY102 in the presence of FOA (Fig. 5A). Deletion of either SBD-A or SBD-B in pDS1 resulted in loss of viability, indicating that two SBDs are necessary for RPAl function. To confirm this, we tested whether viability could be restored by tandem copies of SBD-A or SBD-B. Two copies of domain A were able to complement SBY102, but two copies of domain B were not. Thus, SBD-A has at least one essential feature not present in SBD-B.

Species-specific interactions between RPA and other cellular components have been suggested to account for

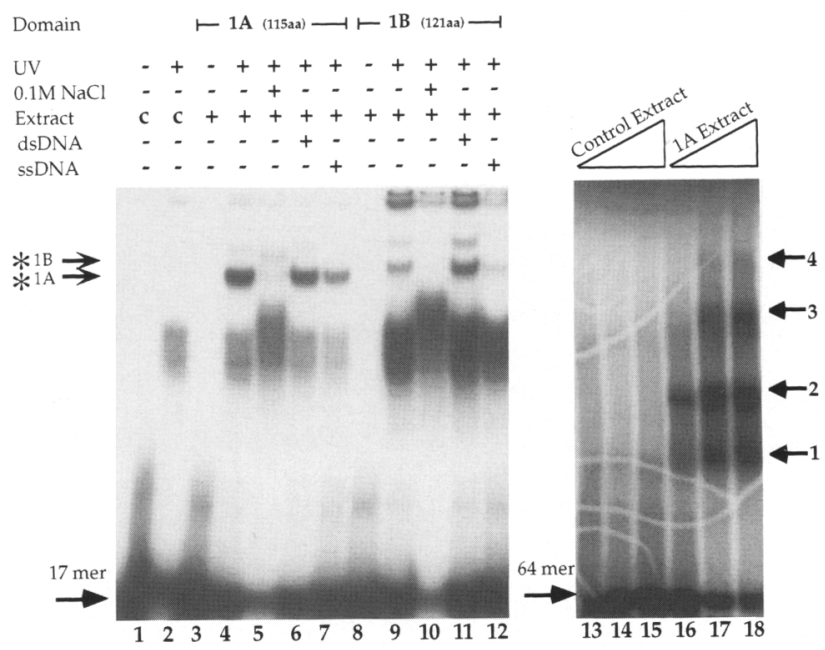

Figure 4. The individual SBDs of RPA1 show ssDNA binding activity in vitro. (Lanes 1-12) An end-labeled 17-mer oligonucleotide was incubated with protein extracts $10.5 \mu \mathrm{g}$ total protein, lanes 1-7; $1.5 \mu \mathrm{g}$, lanes 8-12) made from $E$. coli expressing the indicated domains of the yeast RPAl protein along with various competitors as indicated above the gel. Asterisks mark the positions of the bound oligonucleotides. (c) Control extract from $E$. coli cells carrying the expression vector alone; the smear in lane 2 may represent the binding by Ecssb; (dsDNA and ssDNA) phage lambda DNA before and after heat denaturation, respectively. (Lanes 13-18) An end-labeled 64-mer oligonucleotide was incubated with increasing amounts 15,15 , and $25 \mu \mathrm{g}$ ) of a protein extract made from $E$. coli bearing either the expression vector alone (lanes 13-15) or the vector expressing the A domain of RPAl (lanes 16-18). Binding reactions were cross-linked with UV and analyzed by electrophoresis on $10 \%$ denaturing polyacrylamide gels containing $7 \mathrm{~m}$ urea. Arrows on the right represent stepwise increase in domain A binding to the oligonucleotide.

the inability of ScRPA to function in SV40 DNA replication and for the failure of HsRPA genes to complement yeast RPA mutants (Brill and Stillman 1989, 1991). To determine whether the SBDs make species-specific interactions with other proteins, we replaced SBD-A and SBD-B with homologous domains from human RPAl. Human SBD-A replaced yeast SBD-A efficiently [doubling time (DT) $=140 \mathrm{~min}]$, but human SBD-B conferred a slow-growth phenotype (DT $=400 \mathrm{~min}$ ) when it was substituted for yeast SBD-B (pDS1.1 and pDS1.4 in Fig. $5 \mathrm{~A})$. Interestingly, human SBD-A suppressed the poor growth of the human SBD-B substitution as the double human SBD swap (pDS1.6, DT $=240 \mathrm{~min}$ ) shows noticeably better growth than the human SBD-B swap alone. Although our results suggest that no essential proteinprotein contacts are made through these residues, domains A and B may interact with themselves given improved growth of pDS1.6 compared with pDS1.4 (Fig. 5A).

To test the in vivo roles of the aromatic residues that are believed to contact ssDNA, we mutated the four residues corresponding to W54 and F60 in RPAl to the neutral residue alanine. The single point mutation F238A in 
A

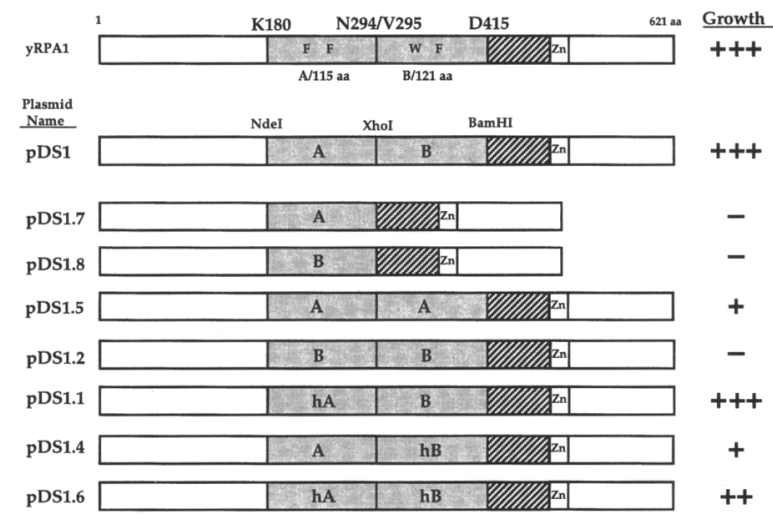

B

\begin{tabular}{|c|c|c|c|}
\hline $\begin{array}{c}\text { Plasmid } \\
\text { Name }\end{array}$ & A & B & Growth \\
\hline pDS1.13 & $\begin{array}{cc}\text { F238 } & \text { F245 } \\
-\quad+\end{array}$ & $\begin{array}{c}\text { W360 F367 } \\
+\quad+\end{array}$ & - \\
\hline pDS1.3 & +- & $+\quad+$ & +++ \\
\hline pDS1.10 & $-\quad-$ & $+\quad+$ & - \\
\hline pDS1.14 & $+\quad+$ & $-\quad+$ & +++ \\
\hline pDS1.16 & ++ & +- & +++ \\
\hline pDS1.11 & ++ & $-\quad-$ & - \\
\hline pDS1.15 & $-\quad+$ & $-\quad+$ & - \\
\hline pDS1.17 & +- & +- & +++ \\
\hline pDS1.12 & $-\quad-$ & $-\quad-$ & - \\
\hline
\end{tabular}

Figure 5. SBD-A and SBD-B are essential in vivo. $(A)$ Plasmids expressing RPAl with the indicated domain swaps were transformed into yeast strain SBY102 and tested for complementation. Growth on FOA was determined at 3 days and assigned a subjective growth rate as indicated by the number of $(+)$ signs on the right. $(B)$ Plasmids expressing full-length RPAl with the indicated wild-type residues $(+)$ or alanine point mutations $(-1$ were transformed into SBY102 and tested for growth on FOA.

SBD-A is lethal, whereas the corresponding mutation W360A in SBD-B is not (Fig. 5B). This critical residue in SBD-A may be responsible for the inability of SBD-B to substitute for SBD-A (pDS1.2 in Fig. 5A). Mutations F245A (in SBD-A) and F367A (in SBD-B) are not lethal alone or in combination (pDS1.3, pDS1.16, pDS1.17 in Fig. 5B). However, the double point mutation W360A, F367A in SBD-B is lethal (pDS1.11), suggesting that these mutations inactivate SBD-B. This result is consistent with reports that W54 and F60 of Ecssb function synergistically to bind ssDNA (Casas-Finet et al. 1987).

sSDNA binding by tandem SBDs requires

"F60" residues

We tested whether SBDs A and B could bind ssDNA stably when expressed in tandem, and what effect mutagenizing the aromatic residues corresponding to Ecssb F60 would have on that binding. Wild-type recombinant protein $\mathrm{RPAl}_{180-415}\left(\mathrm{~A}^{++} / \mathrm{B}^{++}\right)$was capable of binding a labeled oligonucleotide as judged by UV cross-linking and gel shift analysis in a denaturing gel (Fig. 6A).
This 235-amino acid protein appears to bind oligonucleotides as well as equivalent levels of Ecssb (177 amino acids), $\mathrm{RPAl}_{180-485}$ (306 amino acids), and full length RPA1 (621 amino acids), which migrates near the top of the gel (Fig. 6A). Identical levels of double-mutant recombinant protein, in which residues F245 and F367 were both mutated to alanine $\left(\mathrm{A}^{+-} / \mathrm{B}^{+-}\right)$, showed a complete loss of UV-dependent binding. This result is consistent with the fact that the F60 residue of Ecssb is the only residue that cross-links to ssDNA and suggests that F245 and F367 of RPAl contact the ssDNA directly. We also tested whether tandem SBDs are capable of stable ssDNA binding in the absence of UV. Figure $6 \mathrm{~B}$ shows that $\mathrm{RPA}_{180-415}\left(\mathrm{~A}^{++} / \mathrm{B}^{++}\right)$is capable of stable ssDNA binding. However, $\mathrm{RPAl}_{180-415}\left(\mathrm{~A}^{+-}\right)$ $\mathrm{B}^{+-}$) shows greatly diminished binding, consistent with the importance of this residue in ssDNA binding by Ecssb. Surprisingly, this double point mutant, which shows such poor ssDNA binding in vitro, corresponds to the viable mutation in pDS1.17 (Fig. 5B). These results reveal that although ssDNA binding may be reduced drastically in the RPA1-F245A/F367A mutant, additional domains within the RPA complex must contribute to ssDNA binding in vivo (see below).

\section{Characterization of the RPA2 and RPA3 SBDS}

We asked whether SBD-Cs and SBD-Ds / within the RPA2 and RPA3 subunits, respectively) were essential for viability by mutating the two conserved aromatic

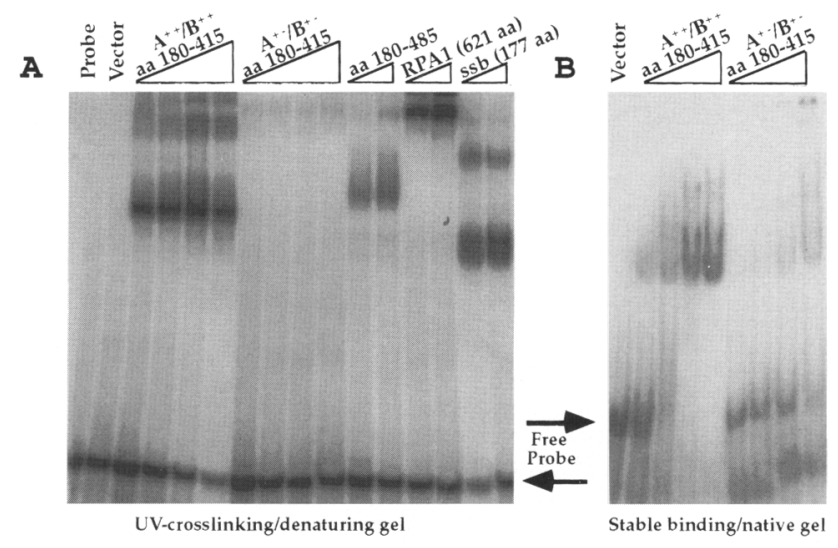

Figure 6. The tandem SBDs of RPA1 require "F60" residues for UV cross-linking and stable ssDNA binding in vitro. (A) An end-labeled 64-mer oligonucleotide was incubated with increasing amounts of extract made from $E$. coli expressing the indicated versions of domains $A$ and $B\{4,8,12$, and $16 \mu \mathrm{g}$ of total protein), domain 180-485 of RPAl (7 and $14 \mu \mathrm{g})$, full-length RPA1 $(7$ and $14 \mu \mathrm{g}$ ), or purified Ecssb protein (50 and $500 \mathrm{ng}$ ). Binding reactions were UV cross-linked and analyzed by electrophoresis on a $10 \%$ denaturing polyacrylamide gel containing $7 \mathrm{M}$ urea. $|B|$ An end-labeled 64-mer oligonucleotide was incubated with increasing amounts of extracts made from $E$. coli expressing the indicated domains of RPAl $(4,8,12$, and $16 \mu \mathrm{g}$ of total protein). Binding reactions were analyzed without denaturation on a $6 \%$ polyacrylamide gel. 
residues alone and in combination. The single mutations Y133A or F143A in the RPA2 subunit are viable, but the double mutant is dead (Fig. 7A). This result is identical to that obtained with SBD-B where replacement of either residue alone was without effect and the double replacement was inviable. This argues that the aromatic residues in SBD-B and SBD-C play similar roles. The results of comparable mutations made in RPA3 are summarized in Figure 7B. Mutations F87A and F97A in SBD-D were not lethal, either alone or in combination. Thus, unlike the three other domains, the two aromatic residues in SBD-D may not play an essential role in ssDNA binding. However, this does not address the question of whether RPA3 is capable of binding ssDNA.

To answer this question, we tested whether the region of RPA3 containing F87 and F97 could replace functionally the corresponding region in RPA2. We replaced 45 residues of RPA2 (G119 to V163) with 44 residues of RPA3 (E74 to K117). These sequences are only $10 \%$ identical and $43 \%$ similar in amino acid sequence. As summarized in Figure 7C, the RPA3 sequence could function in place of the RPA2 sequence in vivo, albeit with a reduction in growth rate. This result indicates that the essential function of the aromatic residues corresponding to Ecssb W54 and F60 in RPA2 is conserved within RPA3.

Attempts to demonstrate ssDNA binding directly with recombinant $\mathrm{p} 36$ and p 3 using photocross-linking were not reproducible. Therefore, we tested whether $\mathrm{p} 36$

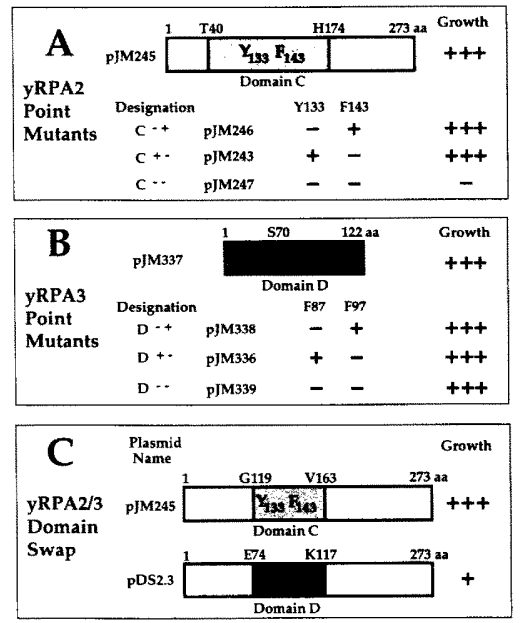

Figure 7. Characterization of SBD-C of RPA2 and SBD-D of RPA3 in vivo. (A) Plasmids expressing RPA2 with the indicated wild-type residues $(+)$ or alanine point mutations $|-|$ were transformed into strain SBY105. Transformants were tested for complementation of the rfa2 null mutation as in Fig. 5. $|B|$ Plasmid DNA expressing RPA3 protein with the indicated wildtype residues $(+)$ or alanine point mutations $(-)$ were transformed into strain SBY111. Complementation of the rfa3 null mutation was tested as in Figure 5. (C) Plasmid DNA expressing RPA2 protein, or a mutation of RPA2 in which residues G119 to V163 were replaced by residues $\mathrm{E} 74$ to $\mathrm{K} 117$ of RPA3 were transformed into strain SBY105. Complementation of the rfa2 null mutation was tested as above.

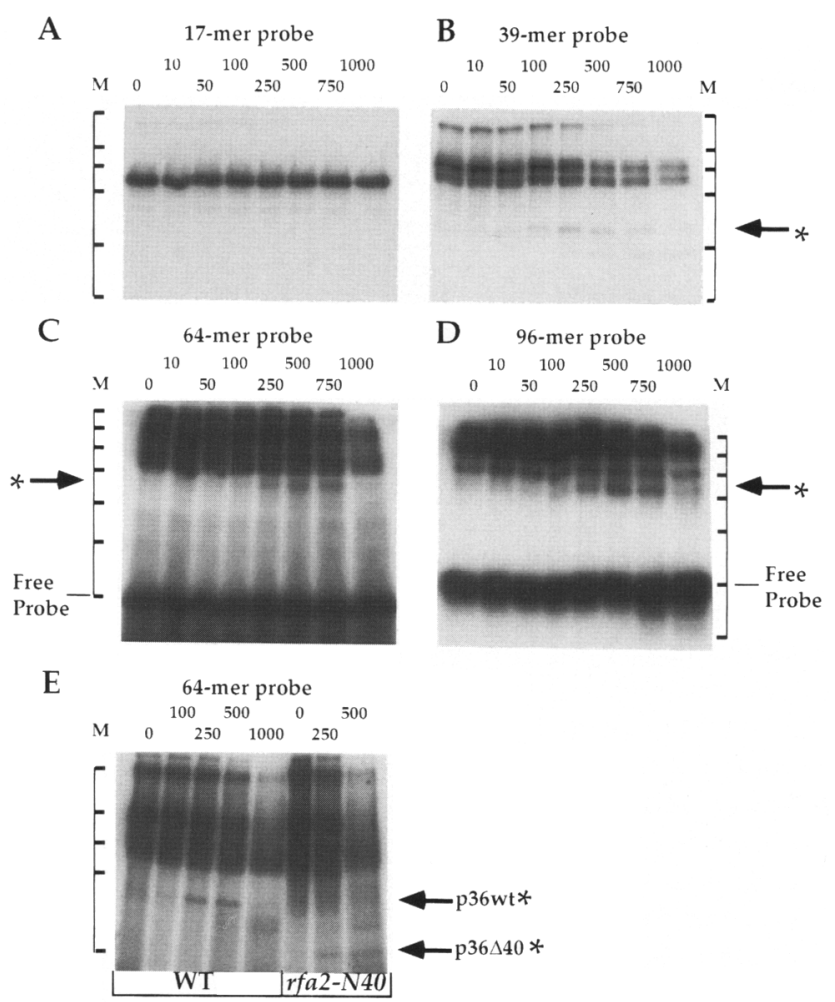

Figure 8. The p36 subunit of RPA binds ssDNA in a lengthand salt-dependent manner. $(A-D)$ The indicated end-labeled oligonucleotide was incubated with $1 \mu \mathrm{g}$ of yeast RPA in the presence of the indicated concentration $(\mathrm{mm})$ of $\mathrm{NaCl}$. Binding reactions were UV cross-linked, boiled in sample buffer, and analyzed by SDS-PAGE in a $17 \%$ polyacrylamide gel. $(E)$ Wildtype (WT) and mutant $(r f a 2-N 40)$ RPA was purified from yeast and used in a cross-linking assay. $|*|$ Positions of p36 bound to oligonucleotides. Molecular mass markers in descending order are $200,116,97,68,45,31$ and $21 \mathrm{kD}$.

and p13 might bind ssDNA as part of the RPA complex. If RPA functions like Ecssb, then these subunits may bind ssDNA only at high salt concentrations. We labeled four oligonucleotides of various lengths and incubated them with RPA under conditions of increasing $\mathrm{NaCl}$ concentration. The resulting complexes were irradiated with UV light and subjected to SDS-PAGE and autoradiography to identify the polypeptides that were crosslinked to the labeled oligonucleotides.

Figure 8A demonstrates that a 17-mer oligonucleotide cross-links exclusively to the $69-\mathrm{kD}$ subunit with RPA binding. This binding is slightly inhibited by 750 and $1000 \mathrm{~mm} \mathrm{NaCl}$. When RPA is cross-linked to a $39-\mathrm{mer}$ oligonucleotide, the cross-linked products appear as several bands $>69 \mathrm{kD}$ in size (Fig. $8 \mathrm{~B}$ ). These bands may represent multiple $69-\mathrm{kD}$ subunits binding to a single 39-mer as reported for glutaraldehyde cross-linking of HsRPA to oligonucleotides (Blackwell and Borowiec 1994). This binding is also slightly sensitive to 750 and $1000 \mathrm{~mm}$ salt. With this oligonucleotide a very weak band of $\sim 50 \mathrm{kD}$ appears at moderate salt concentrations (asterisk, Fig. 8B). 
When RPA was bound to either a 64-mer or a 96-mer oligonucleotide, the high molecular mass forms attributed to cross-linking to the $69-\mathrm{kD}$ subunit are more resistant to 750 and $1000 \mathrm{~mm} \mathrm{NaCl}$. For both the 64-mer and the $96-\mathrm{mer}$, at concentrations $\geqslant 250 \mathrm{mM} \mathrm{NaCl}$, a pronounced new band was observed (asterisks, Fig. 8C,D). The relative molecular mass of this band with the 64mer is $60 \mathrm{kD}$, of which $\sim 22 \mathrm{kD}$ are contributed by the oligonucleotide. The new band with the 96-mer migrates with a mobility of $75 \mathrm{kD}$, of which $31 \mathrm{kD}$ are contributed by the oligonucleotide. From five independent experiments we estimate that the new band corresponds to a protein of $\sim 38 \mathrm{kD}$ that is cross-linked to the ssDNA at $\geqslant 250 \mathrm{~mm} \mathrm{NaCl}$. Our results are consistent with the p36 subunit of ScRPA binding to these longer oligonucleotides at increased salt concentrations. Attempts to identify this new band by immunoblotting with antiserum to p36 failed owing to its low abundance. To confirm that the p36 subunit was responsible for this effect we purified RPA from the viable truncation mutant rfa2-N4O (see Fig. 1) and assayed its salt-dependent ssDNA-binding activity. As shown in Figure $8 \mathrm{E}$ this $\mathrm{mu}$ tant RPA lacks a cross-linking band corresponding to p36, but at 250 and $500 \mathrm{~mm} \mathrm{NaCl}$ a new band of higher mobility appears $(50 \mathrm{kD})$. This result demonstrates that p36 is capable of salt-dependent ssDNA binding. We have not yet observed binding by p13 under these conditions, but, given the genetic results described above for p13, it is possible that each of RPA's three subunits function in ssDNA binding.

\section{Discussion}

We have characterized RPA in yeast, both genetically and biochemically, and our results indicate that RPA is more similar to bacterial SSB than thought previously. RPA contains four essential domains (SBDs), each with a pair of aromatic residues corresponding to W54 and F60 of Ecssb. Like Ecssb, the F60 residues in domains $A$ and $B$ cross-link to ssDNA and are important for stable ssDNA binding in vitro. Unlike Ecssb, the domains are arranged in a hierarchy in terms of their role in ssDNA binding. Within the known ssDNA-binding subunit p69, domain $A$ retains the conserved $W 40$ residue of Ecssb and cannot be replaced by domain $\mathrm{B}$. We also find evidence that p36 (domain $C$ ), which also retains the conserved W40 residue, binds ssDNA when oligonucleotides 39 nucleotides or larger are cross-linked to RPA. Binding of ssDNA to 336 is not unique to yeast RPA as a similar cross-linking band was found in two HsRPA preparations (data not shown). It is interesting that this binding occurs at $\geqslant 0.25 \mathrm{M} \mathrm{NaCl}$, which is very close to the salt concentration at which ssDNA wraps around Ecssb, thus increasing the number of SBDs in contact with the DNA and increasing its affinity for ssDNA.

The pair of aromatic residues in SBD-D within the p13 subunit is not required for viability, and we do not observe any cross-linked proteins of corresponding size (Figure 8). We have not ruled out, however, a role for p13 in ssDNA binding. The 52 -amino acid region that in- cludes this pair of aromatic residues is essential for viability and this region can functionally replace similar residues in SBD-C of p36. Although p13 may simply serve a structural role in RPA, a simpler model is that RPA3 also binds ssDNA in the RPA complex, perhaps during nonessential processes. A trivial explanation for the lack of p13 cross-linking could be that our longest oligonucleotide, a $96-\mathrm{mer}$, was too short. It is now apparent that $\mathrm{p} 36$ and $\mathrm{p} 13$ were not identified previously as ssDNA-binding subunits because a single SBD binds only weakly on its own.

Together, the four SBDs of RPA suggest a structure resembling Ecssb (Fig. 9). An Ecssb protomer is composed of a 115-amino acid ssDNA-binding domain and a 62 -amino acid tail that is dispensable for most activities. Although the secondary structure of the region around W54 and F60 is unknown, it seems likely that this pair of aromatic residues stacks with the nucleotide bases of ssDNA, using two or four protomers depending on the binding mode. We suggest that RPA is composed of a very similar arrangement of 120-amino acid ssDNAbinding domains. But, whereas each protomer is equivalent in Ecssb, the RPA "protomers" have taken on specific functions by virtue of their placement in the heterotrimer.

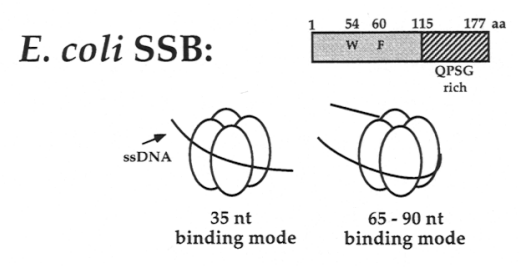

Replication Protein A:
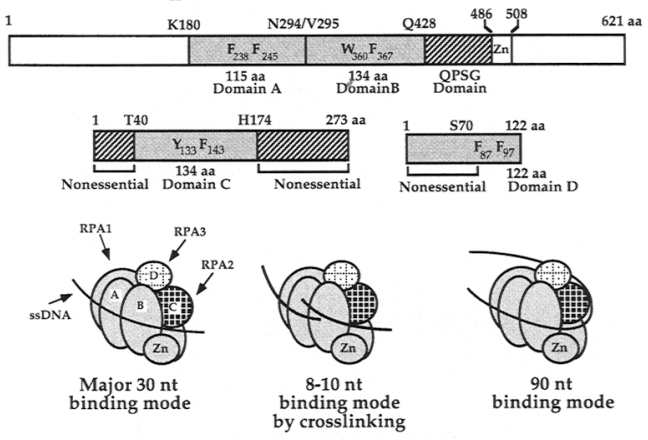

Figure 9. A structural model for RPA. Residues that are important for ssDNA binding are indicated. Binding of ssDNA by p13 is not implied by this model; however, it is centrally located as it may play a role in holding the four SBDs in a stable conformation. Cross-hatched regions are rich in QPSG. In Crithidia $\mathrm{RPAl}$, the 50 -amino acid region downstream of domain $\mathrm{B}$ is $35 \%$ QPSG $(24-26 \%$ in three other species). Crithidia may represent a more ancient and simpler form of RPAl as it lacks the 180-amino acid region upstream of domain A.) The amino-terminal nonessential region of RPA2 is $35-52 \%$ QPSG (four species), and the carboxy-terminal nonessential region is $25-33 \%$ QPSG (four species). In comparison, the SBDs (14 total) are low in QPSG $(17-26 \%)$. 
The multiple binding domains of RPA, combined with at least two salt-dependent binding modes, provide an explanation for the discrepancy in binding-site sizes that have been reported for RPA. As illustrated at the bottom of Figure 9, RPA1, containing the tandemized SBD-A and SBD-B, produces the major 30-nucleotide binding mode at low salt concentrations (Atrazhev et al. 1992; Kim et al. 1992, Mitsis et al. 1993). Individually, SBD-A, SBD-B, and SBD-C are able to make transient, low-affinity interactions with ssDNA, and it is possible to "trap" these events with UV or glutaraldehyde cross-linking, giving rise to a much smaller, 8- to 10-nucleotide binding mode (Blackwell and Borowiec 1994). Finally, given a sufficiently long ssDNA substrate and moderately high ionic strength, a larger, 90-nucleotide binding mode is observed, as was found originally for ScRPA (Alani et al. 1992). We propose that this binding mode arises by the wrapping of ssDNA about the heterotrimer, attributable to interactions with the p36 and perhaps the p13 subunits of RPA, resulting in an increase in ssDNA-binding affinity.

Higher order binding of ssDNA to Ecssb has been known for some time, but its biological function remains a mystery (Griffith et al. 1984; Rigler and Romano 1995). A genetic investigation into the role of higher order binding in $E$. coli is obviously difficult as each protomer is identical. But in eukaryotes, where each protomer has evolved into a separate domain, it is possible to mutate them individually to determine how defects in higher order ssDNA binding affect the various functions of an SSB. Our initial results suggest that higher order binding is essential, because inactivating RPA2 with the double point mutation is lethal.

The four SBDs of RPA represent domains that may have special roles in the processes of DNA replication, repair, and recombination and are potential targets of regulation. The phosphorylation of the p36 subunit may regulate the ability of RPA to bind ssDNA in a higher order complex. One might expect that phosphorylation would reduce its ability to bind ssDNA attributable to charge repulsion. By extension we suggest that $\mathrm{p} 36$ phosphorylation at the replication fork might weaken tightly bound RPA so that it can be displaced by the DNA replication machinery. Although it has been reported that phosphorylation of RPA is not essential in vitro (Henricksen and Wold 1994; Pan et al. 1995), its role in the cell is relatively unexplored. The study of conditional mutants in p36 should reveal the cellular function of higher order ssDNA binding.

The structure/function analysis of RPA addresses indirectly the question of how the subunits of RPA form a complex. We suggest that the SBD domains themselves are involved in subunit interaction, as they are in Ecssb (Williams et al. 1984). In support of this hypothesis, the p36 and p13 subunits are closely related to each other in the SBD domains and are able to form a subcomplex when coexpressed (Henricksen et al. 1994; Stigger et al. 1994). Our results also indicate an additional interaction between the tandem SBDs in RPA1. Replacing both yeast domains with human domains resulted in better growth than replacing SBD-B alone. This suggests a favorable interaction between the human $\mathrm{A}$ and $\mathrm{B}$ domains.

It is an intriguing possibility that RPA and Ecssb arose from the same progenitor $s s b$ gene. We propose that the ancestral protein was a homotetramer that was maintained in its simplest form by the prokaryotes and mitochondria. In eukaryotes some complexity was introduced by gene amplification and recombination resulting in a fusion of two ssDNA-binding domains, which is now RPA1. Two additional copies of the gene gave rise to RPA2 and RPA3 to maintain the four ssDNA binding domains. Some speculative support for this model is provided by the conservation of QPSG-rich domains in the Ecssb tail (65\% QPSG) and some RPA subunits (crosshatched in Fig. 91. We suggest that the amino-terminal domain of RPA2 arose by recombination with the carboxy-terminal QPSG domain of RPA3, which now lacks any tail region. The rearrangment of protein domains in two functionally conserved replication proteins like RPA and Ecssb is extreme but not unprecedented. A similar event has been observed in the sliding clamps of prokaryotes (the dimer $\beta$ ) and eukaryotes (the trimer PCNA) (Kelman and O'Donnell 1995). The identification of four SBDs in RPA eliminates much of the mystery surrounding its heterotrimeric structure and mechanism of ssDNA binding, but it leaves open the questions of why the SBDs are prioritized and why RPA1 has additional nonbinding domains. Answers to these questions should identify the truly eukaryotic properties of RPA.

\section{Materials and methods}

\section{Yeast strains}

Saccharomyces cerevisiae strains SBY102, SBY105, and SBY111 contain chromosomal deletions of RFA1, RFA2, and RFA3, respectively, in the W303-1a background as described (Brill and Stillman 1991) and carry the plasmids pIM114, pJM218, and pIM320, respectively, which contain the respective wild-type gene in YCp50.

\section{DNA constructions}

Plasmid pIM238 is the parent expression vector for all the RFA gene truncations. This plasmid contains the RFA2 promoter and a downstream BamHI site that was constructed by changing the context of the initiating methionine to an NdeI site by PCR amplification and ligation into the centromeric $L E U 2$ vector pRS415. All truncations of the RFA1 RFA2, and RFA3 genes were obtained by 12 rounds of amplification using Vent DNA polymerase and the template plasmids pJM136 (RFA1 with NdeI sites at 605 and 1660 destroyed by site-directed mutagenesis), pIM215 (RFA2 cDNA), and pIM318 (RFA3), respectively (Brill and Stillman 1991). Oligonucleotides for these reactions introduce an upstream initiating methionine in the context of an NdeI site and a downstream stop codon followed by a BamHI site. The digested PCR product was then ligated into the unique NdeI and BamHI sites of pIM238.

Plasmid pET1la and the T7 RNA polymerase system was used for all E. coli expression experiments. Plasmids pET1A and pET1B express the 115-amino acid domain A (K180-N294) and the 121-amino acid domain B (V295-D415) of RPAl, respec- 
tively. pIM145 and pIM146 express the 235-amino acid mutant $(\mathrm{A}+-/ \mathrm{B}+-)$ and wild-type $(\mathrm{A}++/ \mathrm{B}++)$ domains of RPA1, respectively. pIM918 expresses amino acids 180-485 of RPA1. DNA fragments corresponding to these domains were amplified as NdeI-BamHI fragments using pIM136 as template and ligated into pET11a.

Plasmid pDS1 is a yeast shuttle vector that contains the wildtype RFA1 gene on a Sall-BglII fragment ligated into the XholBamHI sites of pRS415. This fragment was obtained by two rounds of amplification using oligonucleotides that introduce the following amino acid changes Q179H, K180M, V295L, P296E, S416G, and K417S. The nucleotide context of these changes puts unique NdeI, XhoI, and BamHI sites flanking domains $A$ and $B$ as shown in Figure 5. Derivatives of $\mathrm{pDS} 1$ shown in Figure $5 \mathrm{~A}$ were obtained by a single round of PCR amplification of domains identified by the alignment in Figure 3 and ligation into pDS1. Point mutant derivatives of pDS1 shown in Figure $5 \mathrm{~B}$ were obtained by two rounds of PCR amplification using mutageneic oligonucleotides that change an aromatic residue to alanine. Typically the A and B domains were joined using a Sall-Xhol junction, which results in minor changes at residues 295 and 296 of the RPAl protein.

Wild-type plasmids pJM245 and pIM 337 contain the RFA2 and $R F A 3$ gene, respectively, cloned into pRS415. Plasmids with point mutations in these genes, as shown in Figure 7A and $\mathrm{B}$, were made with two rounds of amplification using pJM215 and pJM318 as templates to introduce aromatic to alanine mutations. The products were ligated into pRS415. Plasmid pDS2 contains the RFA2 gene with the NdeI and Xhol sites flanking domain $C$. This introduces the amino acid changes N63M and T165E and complements the rfa2 null mutation. pDS2.3 was then constructed by two rounds of amplification replacing the 45 residues G119 to V163 of RPA2 with residues E74 to K117 of RPA3 followed by ligation into the NdeI and XhoI sites of pDS2.

\section{Recombinant protein expression}

BL21(DE3) cells were grown in LB medium containing $0.1 \mathrm{mg} /$ $\mathrm{ml}$ of ampicillin at $23^{\circ} \mathrm{C}$ to $\mathrm{OD}_{600}=0.5$. IPTG was then added to $0.4 \mathrm{~mm}$ for $3 \mathrm{hr}$. Cells were harvested and the bacterial pellet resuspended in 1/10 volume A buffer (Brill and Stillman 1989) with $50 \mathrm{~mm} \mathrm{NaCl}$ and $1 \mathrm{mg} / \mathrm{ml}$ of lysozyme. After incubation on ice for $15 \mathrm{~min}, \mathrm{NP}-40$ was added to a final concentration of $0.1 \%$ and the lysate was subjected to a total of three freezethaw cycles. Chromosomal DNA was dispersed by sonication $3 \times 1 \mathrm{~min}$, on ice, typically with volumes of $20 \mathrm{ml}$. The extract was clarified by centrifugation at $20,000 \mathrm{~g}$ for $20 \mathrm{~min}$ at $4^{\circ} \mathrm{C}$ before use and typically contained $5 \mathrm{mg} / \mathrm{ml}$ of total protein. Soluble protein corresponding to domain A was visible by SDSPAGE and Coomassie staining and estimated to be $0.1 \mathrm{mg} / \mathrm{ml}$. Domains $\mathrm{B}, \mathrm{A} / \mathrm{B}, \mathrm{RPA} 1_{180-415}$, and $\mathrm{RPAl}$ full-length were mostly insoluble and could not be distinguished from the background of soluble E. coli proteins.

\section{DNA-binding assays}

$U V$ cross-linking assay Binding reactions of $10 \mu \mathrm{l}$ containing protein extracts from $E$. coli were incubated with 10,000-15,000 cpm of ${ }^{32} \mathrm{P}$-labeled oligonucleotide under the following conditions: $4 \mathrm{~mm}$ Tris ( $\mathrm{pH} 8.0$ ) $, 40 \mathrm{mM} \mathrm{NaCl}, 6 \%$ glycerol, and 10 $\mu \mathrm{g} / \mathrm{ml}$ of sheared salmon sperm DNA. Reactions were spotted onto a sheet of parafilm, placed on ice, and irradiated with a short-wave UV lamp at a distance of 2 in for $15 \mathrm{~min}$. An equal volume of $2 \times$ gel loading buffer $17 \mathrm{M}$ urea, $10 \mathrm{mM}$ EDTA, $0.05 \%$ xylene cyanol, and $0.05 \%$ bromophenol blue) was added to each sample, which was placed in a microcentrifuge tube and heated for $3 \mathrm{~min}$ at $90^{\circ} \mathrm{C}$. The reactions were then loaded on $10 \%$ polyacrylamide gels $(20: 1$ acrylamide:bis) containing $1 \times \mathrm{TBE}$ and $7 \mathrm{M}$ urea, and subjected to electrophoresis at $10 \mathrm{~V} / \mathrm{cm}$ at room temperature. The gel was then dried and exposed to film.

Stable binding assay Binding reactions of $20 \mu \mathrm{l}$ containing protein extracts from E. coli expressing tandem wild-type or mutant $\mathrm{A} / \mathrm{B}$ domains of RPAl were incubated at room temperature for $20 \mathrm{~min}$ with $10,000-15,000 \mathrm{cpm}$ of ${ }^{32} \mathrm{P}$-labeled oligonucleotide under the following conditions: $4 \mathrm{~mm}$ Tris $(\mathrm{pH} 8.0)$, $40 \mathrm{~mm} \mathrm{NaCl}, 4.5 \%$ glycerol, $150 \mathrm{ng}$ of sheared salmon sperm DNA, and $0.4 \mu \mathrm{g}$ of BSA. Reactions were loaded directly onto $6 \%$ polyacrylamide gels $(37.5: 1$ acrylamide:bis $)$ containing $0.5 \times \mathrm{TBE}$ and subjected to electrophoresis at $10 \mathrm{~V} / \mathrm{cm}$ at room temperature. The gel was then dried and exposed to film.

$U V$ cross-linking to purified SCRPA Binding reactions of 10 $\mu l$ containing $25 \mathrm{~mm}$ HEPES (pH 7.0), $2 \mathrm{~mm}$ DTT, $5 \mu \mathrm{g}$ of BSA, $20,000-30,000 \mathrm{cpm}$ of a ${ }^{32}$ P-labeled oligonucleotide, $1 \mu \mathrm{g}$ of ScRPA, and increasing concentrations of $\mathrm{NaCl}$ were incubated at room temperature for $30 \mathrm{~min}$ and then spotted onto parafilm and irradiated with UV light at $1000 \mathrm{~J} / \mathrm{m}^{2}$ using a Stratalinker (Stratagene). Reactions were placed in microcentrifuge tubes, SDS sample buffer was added, and the reactions were heated at $100^{\circ} \mathrm{C}$ for $5 \mathrm{~min}$. The samples were then loaded onto $17 \%$ SDSPAGE mini-gels and subjected to electrophoresis. The gel was then stained, destained, dried, and exposed to film.

\section{Acknowledgments}

We thank Tom Melendy and Anindya Dutta for human RPA protein, and Julianne Smith for her generous help in RFAl complementation testing. We also thank Michael Hampsey, Tim Lohman, Lenore Neigeborn, and Kiran Madura for many helpful ideas. This work was supported by grant 3904 from the Council for Tobacco Research, USA and the Charles and Johanna Busch Memorial Fund.

The publication costs of this article were defrayed in part by payment of page charges. This article must therefore be hereby marked "advertisement" in accordance with 18 USC section 1734 solely to indicate this fact.

\section{References}

Alani, E., R. Thresher, J.D. Griffith, and R.D. Kolodner. 1992. Characterization of DNA-binding and strand-exchange stimulation properties of $y$-RPA, a yeast single-strand-DNAbinding protein. J. Mol. Biol. 227: 54-71.

Atrazhev, A., S. Zhang, and F. Grosse. 1992. Single-stranded DNA binding protein from calf thymus. Purification, properties, and stimulation of the homologous DNA-polymerase-alpha-primase complex. Eur. J. Biochem. 210: 855-865.

Bayer, I., A. Fliess, J. Greipel, C. Urbanke, and G. Maass. 1989. Modulation of the affinity of the single-stranded DNA-binding protein of Escherichia coli (E. coli SSB) to poly(dT) by site-directed mutagenesis. Eur. I. Biochem. 179: 399-404.

Blackwell, L.J. and J.A. Borowiec. 1994. Human replication protein A binds single-stranded DNA in two distinct complexes. Mol. Cell. Biol. 14: 3993-4001.

Boeke, J.D., J. Trueheart, G. Natsoulis, and G.R. Fink. 1987. 5-Fluoroorotic acid as a selective agent in yeast molecular genetics. Methods Enzymol. 154: 164-175.

Brill, S.J. and B. Stillman. 1989. Yeast replication factor-A functions in the unwinding of the SV40 origin of DNA replica- 
tion. Nature 342: 92-95.

1991. Replication factor-A from Saccharomyces cerevisiae is encoded by three essential genes coordinately expressed at S phase. Genes \& Dev. 5: 1589-1600.

Bujalowski, W. and T.M. Lohman. 1991. Monomers of the Escherichia coli SSB-1 mutant protein bind single-stranded DNA. I. Mol. Biol. 217: 63-74.

Bujalowski, W., L.B. Overman, and T.M. Lohman. 1988. Binding mode transitions of Escherichia coli single strand binding protein-single-stranded DNA complexes. Cation, anion, $\mathrm{pH}$, and binding density effects. I. Biol. Chem. 263: 4629-4640.

Cardoso, M.C., H. Leonhardt, and B. Nadal-Ginard. 1993. Reversal of terminal differentiation and control of DNA replication: Cyclin A and Cdk2 specifically localize at subnuclear sites of DNA replication. Cell 74: 979-992.

Carlini, L.E., R.D. Porter, U. Curth, and C. Urbanke. 1993. Viability and preliminary in vivo characterization of site-directed mutants of Escherichia coli single-stranded DNAbinding protein. Mol. Microbiol. 10: 1067-1075.

Casas-Finet, J.R., M.I. Khamis, A.H. Maki, and J.W. Chase. 1987. Tryptophan 54 and phenylalanine 60 are involved synergistically in the binding of E. coli SSB protein to singlestranded polynucleotides. FEBS Lett. 220: 347-352.

Chrysogelos, S. and J. Griffith. 1982. Escherichia coli singlestrand binding protein organizes single-stranded DNA in nucleosome-like units. Proc. Natl. Acad. Sci. 79: 5803-5807.

Coverley, D., M.K. Kenny, M. Munn, W.D. Rupp, D.P. Lane, and R.D. Wood. 1991. Requirement for the replication protein SSB in human DNA excision repair. Nature 349: 538-541.

Curth, U., I. Greipel, C. Urbanke, and G. Maass. 1993. Multiple binding modes of the single-stranded DNA binding protein from Escherichia coli as detected by tryptophan fluorescence and site-directed mutagenesis. Biochemistry 32: 2585-2591.

Curth, U., C. Urbanke, J. Greipel, H. Gerberding, V. Tiranti, and M. Zeviani. 1994. Single-stranded-DNA-binding proteins from human mitochondria and Escherichia coli have analogous physicochemical properties. Eur. J. Biochem. 221: 435443.

Din, S., S. Brill, M.P. Fairman, and B. Stillman. 1990. Cell-cycleregulated phosphorylation of DNA replication factor A from human and yeast cells. Genes \& Dev. 4: 968-977.

Dutta, A. and B. Stillman. 1992. cdc2 family kinases phosphorylate a human cell DNA replication factor, RPA, and activate DNA replication. EMBO J. 11: 2189-2199.

Dutta, A., J.M. Ruppert, J.C. Aster, and E. Winchester. 1993. Inhibition of DNA replication factor RPA by p53. Nature 365: 79-82.

Erdile, L.F., W.D. Heyer, R. Kolodner, and T.J. Kelly. 1991. Characterization of a cDNA encoding the $70-\mathrm{kDa}$ single-stranded DNA-binding subunit of human replication protein $\mathrm{A}$ and the role of the protein in DNA replication. $/$. Biol. Chem. 266: 12090-12098.

Fairman, M.P. and B. Stillman. 1988. Cellular factors required for multiple stages of SV40 replication in vitro. EMBO $J$ 7: 1211-1218.

Fotedar, R. and J.M. Roberts. 1992. Cell cycle regulated phosphorylation of RPA-32 occurs within the replication initiation complex. EMBO I. 11: 2177-2187.

Ghrir, R., J.P. Lecaer, C. Dufresne, and M. Gueride. 1991. Primary structure of the two variants of Xenopus laevis mtSSB, a mitochondrial DNA binding protein. Arch. Biochem. Biophys. 291: 395-400.

Griffith, J.D., L.D. Harris, and J.D. Register. 1984. Visualization of SSB-ssDNA complexes active in the assembly of stable RecA-DNA filaments. Cold Spring Harbor Symp. Quant. Biol. 49: 553-559.
Guzder, S.N., Y. Habraken, P. Sung, L. Prakash, and S. Prakash. 1995. Reconstitution of yeast nucleotide excision repair with purified Rad proteins, replication protein A, and transcription factor TFIIH. J. Biol. Chem. 270: 12973-12976.

He, Z., B.T. Brinton, J. Greenblatt, J.A. Hassell, and C.J. Ingles. 1993. The transactivator proteins VP16 and GAL4 bind replication factor A. Cell 73: 1223-1232.

He, Z., L.A. Henricksen, M.S. Wold, and C.J. Ingles. 1995. RPA involvement in the damage-recognition and incision steps of nucleotide excision repair. Nature 374: 566-569.

Henricksen, L.A. and M.S. Wold. 1994. Replication protein A mutants lacking phosphorylation sites for p34cdc2 kinase support DNA replication. /. Biol. Chem. 269: 24203-24208.

Henricksen, L.A., C.B. Umbricht, and M.S. Wold. 1994. Recombinant replication protein A: Expression, complex formation, and functional characterization. I. Biol. Chem. 269: 11121-11132.

Heyer, W.D., M.R. Rao, L.F. Erdile, T.J. Kelly, and R.D. Kolodner. 1990. An essential Saccharomyces cerevisiae singlestranded DNA binding protein is homologous to the large subunit of human RP-A. EMBO J. 9: 2321-2329.

Kelman, Z. and M. O'Donnell. 1995. Structural and functional similarities of prokaryotic and eukaryotic DNA polymerase sliding clamps. Nucleic Acids Res. 23: 3613-3620.

Keshav, K.F., C. Chen, and A. Dutta. 1995. Rpa4, a homolog of the 34-kilodalton subunit of the replication protein A complex. Mol. Cell. Biol. 15: 3119-3128.

Khamis, M.I., J.R. Casas-Finet, A.H. Maki, J.B. Murphy, and J.W. Chase. 1987. Investigation of the role of individual tryptophan residues in the binding of Escherichia coli singlestranded DNA binding protein to single-stranded polynucleotides. A study by optical detection of magnetic resonance and site-selected mutagenesis. I. Biol. Chem. 262: 1093810945.

Kim, C., R.O. Snyder, and M.S. Wold. 1992. Binding properties of replication protein A from human and yeast cells. Mol. Cell. Biol. 12: 3050-3059.

Kim, C., B.F. Paulus, and M.S. Wold. 1994. Interactions of human replication protein A with oligonucleotides. Biochem istry 33: 14197-14206.

Li, R. and M.R. Botchan. 1993. The acidic transcriptional activation domains of VP16 and p53 bind the cellular replication protein $A$ and stimulate in vitro BPV-1 DNA replication. Cell 73: 1207-1221.

Lohman, T.M. and M.E. Ferrari. 1994. Escherichia coli singlestranded DNA-binding protein: Multiple DNA-binding modes and cooperativities. Annu. Rev. Biochem. 63: 527570.

Lohman, T.M. and L.B. Overman. 1985. Two binding modes in Escherichia coli single strand binding protein-single stranded DNA complexes. Modulation by $\mathrm{NaCl}$ concentration. J. Biol. Chem. 260: 3594-3603.

Luche, R.M., W.C. Smart, T. Marion, M. Tillman, R.A. Sumrada, and T.G. Cooper. 1993. Saccharomyces cerevisiae BUF protein binds to sequences participating in DNA replication in addition to those mediating transcriptional repression (URS1) and activation. Mol. Cell. Biol. 13: 5749-5761.

Merrill, B.M., K.R. Williams, J.W. Chase, and W.H. Konigsberg. 1984. Photochemical cross-linking of the Escherichia coli single-stranded DNA-binding protein to oligodeoxynucleotides. Identification of phenylalanine 60 as the site of crosslinking. J. Biol. Chem. 259: 10850-10856.

Mitsis, P.G., S.C. Kowalczykowski, and I.R. Lehman. 1993. A single-stranded DNA binding protein from Drosophila melanogaster: Characterization of the heterotrimeric protein and its interaction with single-stranded DNA. Biochemistry 
32: 5257-5266.

Moore, S.P., L. Erdile, T. Kelly, and R. Fishel. 1991. The human homologous pairing protein HPP-1 is specifically stimulated by the cognate single-stranded binding protein hRP-A. Proc. Natl. Acad. Sci. 88: 9067-9071.

O'Donnell, M., R. Onrust, F.B. Dean, M. Chen, and J. Hurwitz. 1993. Homology in accessory proteins of replicative polymerases-E. coli to humans. Nucleic Acids Res. 21: 1-3.

Pan, Z.Q., C.H. Park, A.A. Amin, J. Hurwitz, and A. Sancar. 1995. Phosphorylated and unphosphorylated forms of human single-stranded DNA-binding protein are equally active in simian virus 40 DNA replication and in nucleotide excision repair. Proc. Natl. Acad. Sci. 92: 4636-4640.

Rigler, M.N. and L.J. Romano. 1995. Differences in the mechanism of stimulation of T7 DNA polymerase by two binding modes of Escherichia coli single-stranded DNA-binding protein. I. Biol. Chem. 270: 8910-8919.

Singh, K.K. and L. Samson. 1995. Replication protein A binds to regulatory elements in yeast DNA repair and DNA metabolism genes. Proc. Nat1. Acad. Sci. 92: 4907-4911.

Smith, J. and R. Rothstein. 1995. A mutation in the gene encoding the Saccharomyces cerevisiae single-stranded DNAbinding protein Rfal stimulates a RAD52-independent pathway for direct-repeat recombination. Mol. Cell. Biol. 15: $1632-1641$.

Stigger, E., F.B. Dean, J. Hurwitz, and S.H. Lee. 1994. Reconstitution of functional human single-stranded DNA-binding protein from individual subunits expressed by recombinant baculoviruses. Proc. Natl. Acad. Sci. 91: 579-583.

Thommes, P., C.L. Farr, R.F. Marton, L.S. Kaguni, and S. Cotterill. 1995. Mitochondrial single-stranded DNA-binding protein from Drosophila embryos. Physical and biochemical characterization. I. Biol. Chem. 270: 21137-21143.

Tiranti, V., M. Rocchi, S. DiDonato, and M. Zeviani. 1993. Cloning of human and rat cDNAs encoding the mitochondrial single-stranded DNA-binding protein (SSB). Gene 126: 219-225.

Van Dyck, E., F. Foury, B. Stillman, and S. Brill. 1992. A singlestranded DNA binding protein required for mitochondrial DNA replication in $S$. cerevisiae is homologous to $E$. coli SSB. EMBO I. 11: 3421-3430.

Williams, K.R., E.K. Spicer, M.B. LoPresti, R.A. Guggenheimer, and J.W. Chase. 1983. Limited proteolysis studies on the Escherichia coli single-stranded DNA binding protein. Evidence for a functionally homologous domain in both the Escherichia coli and T4 DNA binding proteins. 1. Biol. Chem. 258: 3346-3355.

Williams, K.R., J.B. Murphy, and J.W. Chase. 1984. Characterization of the structural and functional defect in the Escherichia coli single-stranded DNA binding protein encoded by the ssb-1 mutant gene. Expression of the ssb-1 gene under lambda pL regulation. I. Biol. Chem. 259: 11804-11811.

Wobbe, C.R., L. Weissbach, J.A. Borowiec, F.B. Dean, Y. Murakami, P. Bullock, and J. Hurwitz. 1987. Replication of simian virus 40 origin-containing DNA in vitro with purified proteins. Proc. Nat1. Acad. Sci. 84: 1834-1838.

Wold, M.S. and T. Kelly. 1988. Purification and characterization of replication protein $\mathrm{A}$, a cellular protein required for in vitro replication of simian virus 40 DNA. Proc. Natl. Acad. Sci. 85: 2523-2527.

Wold, M.S., D.H. Weinberg, D.M. Virshup, J.J. Li, and T.J. Kelly. 1989. Identification of cellular proteins required for simian virus 40 DNA replication. J. Biol. Chem. 264: 2801-2809. 


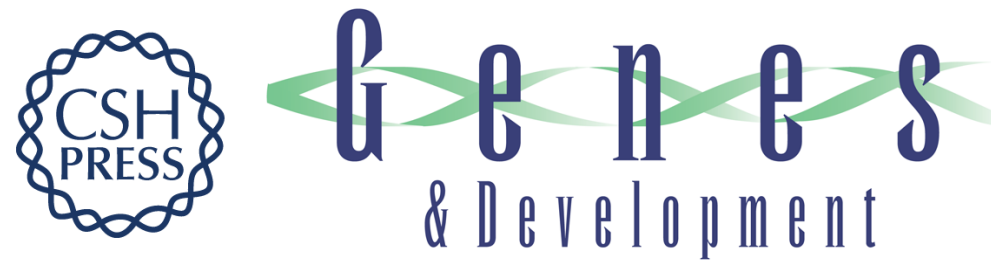

\section{A hierarchy of SSB protomers in replication protein A.}

D Philipova, J R Mullen, H S Maniar, et al.

Genes Dev. 1996, 10:

Access the most recent version at doi:10.1101/gad.10.17.2222

References This article cites 56 articles, 28 of which can be accessed free at:

http://genesdev.cshlp.org/content/10/17/2222.full.html\#ref-list-1

\section{License}

Email Alerting

Receive free email alerts when new articles cite this article - sign up in the box at the top Service right corner of the article or click here.

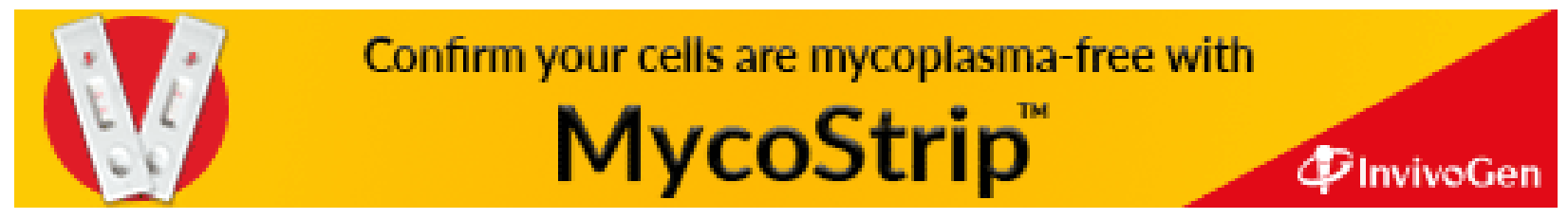

